\title{
In Defense of Qualitative Changes in Development
}

\section{Citation}

Kagan, Jerome. 2008. "In Defense of Qualitative Changes in Development." Child Development 79 (6): 1606-24. https://doi.org/10.1111/j.1467-8624.2008.01211.x.

\section{Permanent link}

http://nrs.harvard.edu/urn-3:HUL.InstRepos:37964397

\section{Terms of Use}

This article was downloaded from Harvard University's DASH repository, and is made available under the terms and conditions applicable to Other Posted Material, as set forth at http:// nrs.harvard.edu/urn-3:HUL.InstRepos:dash.current.terms-of-use\#LAA

\section{Share Your Story}

The Harvard community has made this article openly available.

Please share how this access benefits you. Submit a story.

Accessibility 


\title{
In Defense of Qualitative Changes in Development
}

\author{
Jerome Kagan \\ Harvard University
}

\begin{abstract}
The balance between the preservation of early cognitive functions and serious transformations on these functions shifts across time. Piaget's writings, which favored transformations, are being replaced by writings that emphasize continuities between select cognitive functions of infants and older children. The claim that young infants possess elements present in the older child's concepts of number, physical impossibility, and object permanence is vulnerable to criticism because the inferences are based primarily on the single measure of change in looking time. It is suggested that investigators use unique constructs to describe phenomena observed in young infants that appear, on the surface, to resemble the psychological competences observed during later developmental stages.
\end{abstract}

The primary goal of scientists working in varied disciplines is to explain how a phenomenon of interest developed its observed form. A central theoretical issue in this search centers on the degree to which the current event contains some features that were present earlier and contribute to the contemporary observation. Darwin's great insight was to recognize that many of the anatomical features and functions of mammals were either absent or assumed a very different pattern in the organisms that lived millions of years earlier from which they presumably evolved. For example, the convoluted cortex of humans is not present in fish, and although the three bones of the human middle ear are derivatives of a set of bones in the fish jaw, they have a qualitatively different structure and function in the two species. Thus, it is correct to say that the bones of the fish jaw preceded the bones of the middle ear but incorrect to declare that the functions and features of the former structure contribute to human hearing.

The principle that some elements are preserved and others are transformed or lost applies to developmental stages within a species. On the one hand, the glial cells of the young embryo that guide newly created neurons to various cortical layers disappear once the mature neurons arrive at their final destination (Rakic, 1995), and the motility patterns of newly hatched birds pecking at the ground have no par-

I thank Richard Aslin, Susan Carey, Leslie Cohen, Marshall Haith, David Moore, Charles A. Nelson, Nora Newcombe, J. Steven Reznick, and Jay Schulkin for comments on an early draft. The incentive for this article was a dinner conversation with Michael Lewis at the 2007 meeting of Society for Research in Child Development in Boston.

Correspondence concerning this article should be addressed to Jerome Kagan, Department of Psychology, Harvard University, Cambridge, MA 02138. Electronic mail may be sent to jk@wjh. harvard.edu. allel in the motor profiles of the developing embryo (Hamburger, 1975). On the other hand, many structures and functions of the embryo's heart and mouth, once they appear, are preserved indefinitely.

The balance between transformation and preservation, which has always been a seminal node of controversy among developmental psychologists, has shifted over time as a function of new technologies, discoveries in allied disciplines, the need to replace a flawed theoretical view, and always the intellectual climate. Many social scientists had attributed the differences in academic achievement between the children of early 20th-century European immigrants to America and those of more affluent, indigenous families to the preservation of early habits and skills acquired within the family. A 1914 government pamphlet for mothers contained a warning that, although it rested on little evidence, reified the conviction that first impressions can have profound influences on the future: "The first nervous impulses which pass through the baby's eyes, ears, finger, or mouth to the tender brain make a pathway for itself; the next time another impulse travels over the same path, it deepens the impression of the first" (West, 1914, p. 59).

This belief in the preservation of the products of early experiences, which was central to behaviorism and psychoanalytic theory, thrived for over 50 years. However, the emergence of a new point of view was inevitable when the accumulated evidence failed to support strong versions of this hypothesis. Ethologists, especially Lorenz (1958) and Tinbergen (1951), who anticipated the ascent of biological mechanisms, recruited interest to the biologically prepared competences of young organisms that might be components

(C) 2008, Copyright the Author(s)

Journal Compilation (C) 2008, Society for Research in Child Development, Inc All rights reserved. 0009-3920/2008/7906-0003 
of later functioning. Most new scientific ideas require between 40 and 50 years before they become popular bases for inquiry. By the late 1990s, technical reports describing biologically prepared conceptual functions in young infants that shared features with those of older children began to fill journal pages (Baillargeon, 1994; Dehaene, 1997; Saxe \& Carey, 2006; Spelke, 1994; Spelke \& Kinzler, 2007; Wynn, 1992).

When understanding of a prolonged developmental cascade is lean, and it is difficult to imagine the intervening stages, there is a strong temptation to assume the smallest possible number of transformations between early and later phenomena in order to be loyal to the principle of parsimony. That is one reason why the 18th-century preformationists assumed that a miniature infant was present in the newly fertilized egg and why Havelock Ellis perceived a link between the look of satisfaction on the face of a nursing infant and the facial expression of lovers lost in the ecstasy of their sexual caresses (Ellis, 1900). Our fragile understanding of the degree to which the behavioral, cognitive, and emotional features of the young infant participate in more mature forms tempts theorists to assume that the early representations and functions are both necessary for, and contain some features of, those that characterize the psychology of school-aged children.

However, the habit of applying the same constructs to explain early and later performances, based on presumed similarities between the bases for early and later behaviors, does not guarantee that the initial and later forms were mediated by the same mechanism. The presence of a reliable smile to an approaching adult, which usually emerges between 3 and 5 months, reflects the fact that the infant is now able to assimilate the person's features to their schemata for the adults with whom they interact regularly. It is unlikely that this mechanism is the reason why an adolescent smiles upon greeting a close friend. Twoweek-olds and 2-year-olds are likely to protrude their tongue following the same act by an adult (Meltzoff \& Moore, 1977), but young infants also protrude their tongue to a slim pencil approaching their mouth because infants use their tongue to explore objects close to their faces (Jacobson, 1979; Jones, 1996; Nakagawa, Sukigara, \& Benga, 2003). Hence, if the older child's behavior is called imitation, a new term should be invented to describe the apparently similar behavior of the young infant. Earlier generations of psychologists assumed that scores on the test items of the Bayley developmental scale for infants and those on the Wechsler Intelligence Scale for schoolaged children represented the same psychological construct, called intelligence. However, the magni- tudes of the correlations between the Bayley scores at 3 or 8 months and the IQ scores of older children are minimal (McCall, Eichorn, \& Hogarty, 1977); hence, the infant competences should be given a different name.

The uncritical use of the same semantic term to name early and later behavioral profiles that are phenotypically distinct and that might rest on different foundations may tempt less sophisticated readers to assume that the two phenomena are exemplars of the same process. These readers should appreciate that current evidence has not yet proven with certainty that any representation, emotion, or cognitive competence present in healthy 6-month-olds is contained in the psychological functions of older children. The mind possesses a small number of stubborn biases that color the initial perception of events and the conception of the hidden structures and functions that lie beneath what is observed. One of the most profound biases, which children honor, is that "things" possess an essence that is unchanging despite surface malleability. Although young infants possess some sensory, perceptual, and motor abilities that are preserved indefinitely (e.g., the detection of sweet tastes and sounds and an automatic orienting of the eyes and head to a moving stimulus), some scholars have posited cognitive competences that go beyond these talents to include functions that are more seriously symbolic or conceptual in nature (Baillargeon, 1994; Spelke, 1994; Wynn, 1998). This claim deserves careful analysis because, if valid, it has the potential to alter our understanding of the infant and development in a radical way.

This issue assumes two major forms in contemporary research: the preservation of early emotional attachments to caretakers and the preservation of early cognitive functions. Discussion of the former has been substantial (Kagan, 1981). Hence, this article discusses only the latter issue and continues a critique initiated by others (Bogartz, Shinskey, \& Schilling, 2000; Bogartz, Shinskey, \& Speaker, 1997; Cashon \& Cohen, 2000; Cohen \& Cashon, 2006; Haith, 1998; Haith \& Benson, 1998; Mandler, 2004).

The nub of the controversy centers on how much (or how little) transformation of the infant's psychological structures occurs as the child grows. If the events that transpire after 6-8 months alter early structures only quantitatively, the consequences of lawful brain growth and later experiences would seem less interesting than they would be if these changes produced qualitative transformations on the original functions. There is an important difference in meaning between (a) "The newborn's fingers closed on the object placed in its palm" and (b) "The 
newborn possesses a disposition for possessiveness." Many 19th-century observers cited the newborn's reflex reaction as the basis for the validity of the second statement (Fiske, 1883).

The histories of scientific controversies reveal that when two groups of sophisticated investigators disagree on the interpretation of a corpus of evidence, later inquiry usually indicates that the most fruitful explanation differs from the one promoted by either group. Early 20th-century physicists argued over whether light was a wave (the classical view) or a particle (the new quantum position). Bohr suggested that physicists should not ask what light "is" but rather how light behaves under specific experimental conditions because the experimental arrangement determines whether a wave or a particle interpretation is the most defensible. The consensus among neuroscientists working in the 1920s was that all synaptic transmission in the brain was electrical in nature. This view was challenged by a small group claiming transmission was chemical. We now appreciate that although most synapses are chemical, both mechanisms occur (Valenstein, 2005). This issue is important enough to return to it again with a different organization of facts and from a slightly different point of view.

\section{Schemata and Semantic Forms}

The psychologists who remain skeptical of the nativist claims for preservation of select early cognitive functions believe that the young infant's knowledge is contained in schemata and sensorimotor structures, whereas the older child's knowledge combines these two earlier forms with semantic networks and the ability to infer events that were not experienced. This suggestion implies a discontinuity in cognitive development because the features and organizations of the early functions differ seriously from those operative later (Cohen \& Cashon, 2006; Haith \& Benson, 1998; Kagan, 2002; Mandler, 2004). A schema is defined as a representation of the patterned perceptual features of an event and need not possess a semantic component or an inference as to its origin. The young infant's representation of a caretaker's face is an obvious example. The primary features of schemata for visual events are spatial extent, shape, color, contrast, motion, symmetry, angularity, circularity, and density of contour.

Eleven-year-old Mayan Indian children living in a small isolated, impoverished village in northwest Guatemala performed as well as 11-year-old Boston children when asked to recognize, following a 2-day delay, a large number of color photographs of unfamiliar objects for which they had no names, such as telescope, toaster, and golf club. Both groups of children correctly recognized the pictures close to $90 \%$ of the time (Kagan, Klein, Haith, \& Morrison, 1973). It is likely that the excellent memory performance of the Mayan children was mediated by the schemata for the pictures they acquired during familiarization.

Infants, like older children, create schematic concepts or prototypes that are "averages" of repeated exposures to the same class of events. Eight-montholds have already acquired schematic concepts for the acoustic envelopes of the vowels and consonantvowel combinations of their language. However, they lose the ability to distinguish between phonemes that resemble the speech sounds they hear but do not occur frequently (Doupe \& Kuhl, 1999). The same phenomenon occurs for schemata representing the mouth movements of speakers (Weikum et al., 2007). Infants can also create schematic concepts for temporal patterns of unfamiliar vocal sounds. Seven-montholds first heard a 2-min speech sample containing three representations of each of 16, three-syllable utterances of the form $a-b-a$, but the syllables in each of the utterances were different. The only feature shared by all the utterances was that the first and third syllables were identical. After the infants were familiarized with this pattern, they heard either an utterance of the same form-a-b-a-or a new set of three syllables with a new form; for example, $a-b-b$. The infants were more attentive to the unfamiliar $a-b-b$ pattern, suggesting that they had created schematic concepts for the temporal pattern of these meaningless vocal sounds (Marcus, Vijayan, Rao, \& Vishton, 1999).

An important distinction between schemata and semantic structures is that only the latter imply both the essential features a referent possesses and some features it does not possess. This logic does not apply to schemata. The sentence, "The leaf is on the ground," implies that there was a time in the past when it was not on the ground; the schema of a leaf on a lawn does not contain that extra knowledge. A second distinction is that most of the time schemata can be transformed without any accompanying cognitive tension. Dreams and reveries provide classic examples. The image of a smiling face can turn into a pumpkin without any of the cognitive dissonance that would occur if a person read, "A smiling face is a pumpkin." Einstein's image of riding a light wave is said to have been one of the origins of his theory of special relativity. However, the printed sentence, "Humans can move at the speed of light" would evoke in most readers an immediate sense of impossibility. 
An important difference between schemata and semantic forms involves their relations to other structures. The relations of similarity, part-whole, and contingency apply to both schemata and semantic forms, even though the specific attributes that define these relations are different for the two structures. Some relations, however, apply only to semantic structures. Only semantic forms possess the quasilogical relations that take the form of hierarchically nested categories for objects and events (called hyponyms) and opposites for qualities (antonyms). These relations assume special prominence after 5 or 6 years of age. Most adults treat the semantic form "dog" as a logically necessary member of the semantic category "animal." Schemata do not nest into sets of hierarchical categories.

Semantic structures vary in their schematic contribution; hence, psychologists compare concrete with abstract nouns. Words like meaning and truth have far less schematic content than girl or table (Warrington \& McCarthy, 1987). The different properties of semantic and schematic representations are due, in part, to the differential participation of the right and left hemispheres. The right hemisphere appears to be biologically prepared to process words with a rich schematic contribution more efficiently than it processes abstract words (Beeman \& Chiarello, 1998; Deloche, Seron, Scius, \& Segui, 1987; Ivry \& Lebby, 1998). The meaning of the semantic term big depends on the specific schemata that are activated. If the child retrieved a schema for trains, big meant long. If, however, the child activated the schema for pumpkins, big meant a large area, and if the activated schema was a building, big meant tall (Sera \& Smith, 1990). The semantic meaning of big varied with the schemata the child activated.

Schemata are used primarily to recognize events, places, and objects experienced in the past and often include representations of the background contexts in which events appear (Moore \& Meltzoff, 2004). By contrast, semantic representations, which are often free of contextual information, are used primarily for classification, inference, comprehension of communications, and understanding causal sequences. The critical point is that schemata and semantic representations for an event award have different meanings to the predicate "know." Indeed, infants who normally treat a picture as discrepant from a familiarization set do not do so when they hear the same verbal label (a nonsense word) accompany the presentation of all stimuli during the familiarization trials (Plunkett, $\mathrm{Hu}$ \& Cohen, 2008). This observation implies that combining semantic information with schemata can mute the physical differences between the perceptual representations. The act of naming apples, oranges, and kiwi fruit dilutes, at least for the moment, the mind's awareness of the perceptual distinctions among these objects.

The differences between schemata and semantic forms are sufficiently salient to warrant asking whether the infant's ability to perceive the difference between arrays of two and four circles reflects the same competence that underlies the ability of 10-year-olds to learn the names for cardinal numbers and to appreciate that they form an ordinal scale of magnitude. A schema for an event, or schematic prototype for a category of event, can exist without any support from semantic elements; hence, the former are to be distinguished from semantic concepts. I would be surprised, and stare for a few seconds, if the number of books on the shelf several feet in front of my desk (and in my direct line of vision) were altered because the new display would violate my schema for that scene. However, I have no idea of the number of books on the shelf. Children watching a video of two chromosomes separating during mitosis will create a perceptual representation for the sequence without any conceptual understanding of what is happening. Young infants and many animal species can discriminate between pictures of an elm tree and an elephant and between parallel and nonparallel lines. But this evidence does not mean that they possess the semantic concepts plant, animal, or parallel.

It is also the case that individuals can have some semantic understanding of a phenomenon without a corresponding set of schematic representations. I know that if I were bitten by an Anopheles mosquito infected with malarial parasites I would come down with a fever, even though I have no schemata for the parasite or the toxins it produces in my body. The extensive literature showing that infants under 8 months display increased attentiveness to events that violate a perceptual expectation does not require positing any semantic representation implying an understanding of the event's origins or consequences. This suggestion does not mean that young infants do not possess semantically based conceptual representations, only that this hypothesis is not yet proven beyond reasonable doubt (Aslin, 2000).

\section{The Source of Evidence}

The meaning and validity of every scientific conclusion based on empirical data always rest on its source of evidence. This principle is one of the most important dividends of the 20th-century advances in 
physics that culminated in quantum mechanics. The statement that turtles and crocodiles are phylogenetically distant is true if similarity in their skeletons is the source of information but false if similarity in DNA strings is the evidence.

This principle is relevant to the concerns of this article because the evidence for most claims about infants' conceptual capacities is total time attending to particular events rather than other indexes of attention, such as duration of the first fixation, the longest fixation, the number of times the infant looks away from the stimulus, and the number of shifts of attention between a pair of events. Aslin (2007) notes that these variables might reflect different cognitive processes, a position articulated by Lewis (1967) over 40 years ago. This possibility is supported by the fact that infants younger than 1 year who displayed frequent attention shifts between a pair of stimuli, together with shorter individual fixations, showed larger increases in attention to a novel event than others (Frick \& Colombo, 1996; Rose, Feldman, \& Jankowski, 2003). In addition, the number of shifts between a pair of stimuli distinguished between drawings with different element densities better than total fixation time (Tan \& Bryant, 2000) and the mean and the longest fixation time often invite different conclusions (Courage, Reynolds, \& Richards, 2006).

In addition, most investigators probing infants' concepts do not quantify brain profiles, autonomic reactions, conditioned operants, facial expressions, crying, vocalizing, or smiling as possible indexes of the state provoked by violation of an expectation. The essential premise in the design of most experiments is that unexpected events recruit longer bouts of attention than those that are expected. These investigators assume implicitly that events that do not match an acquired perceptual representation create a state that neuroscientists believe is accompanied by activation of the parahippocampal region, amygdala, and parietal lobe and, as a consequence, a prolonged orientation (Joseph et al., 2006). However, I will orient and stare out the window of my study for several seconds if I hear an unexpected outside sound and will gaze at the faucet in my kitchen if no water flows when I turn it, without any understanding of the origin of the sound or the reason for the failure of water to flow. A prolonged orientation to an unexpected event is not synonymous with knowing or inferring, anything about its origins or conceptual category (Saffran, 2001). Rather, looking reflects a temporary state of uncertainty. That is why 6- and 9-month-olds look at their mother when an unexpected event occurs (Walden, Kim, McCoy, \& Karrass, 2007).
Moreover, failure to show a longer bout of attention to one event compared with another does not mean that the infant did not detect the distinctive features of the two events or did not experience an expectancy violation. Infants familiarized on a circle enclosing two dark, horizontally placed circles in the upper part of the design showed increased looking if the horizontally placed circles were vertical but did not show prolonged looking if the circles were replaced with squares, even though infants can detect the difference between squares and circles (Kagan, Linn, Mount, \& Reznick, 1979). Thus, failure to show increased attention and the display of increased attention are ambiguous and do not demand only one interpretation.

\section{A Trio of Influences on Looking}

Many investigators ignore three factors that can influence duration of attention to an event: (a) the possibility that the relation between unfamiliarity and duration of looking is curvilinear rather than linear, (b) the influence of brain maturation (i.e., uniform changes in all healthy infants in brain structure and physiology over time), and (c) the significance of the physical features of the stimuli.

\section{Linear or Curvilinear Functions}

Although the developmental scientists who rely on total duration of attention never say so explicitly, they assume implicitly that the relation between expectation and looking time is linear. The less expected an event (and, by inference, the more discrepant it is from the infant's schemata), the longer the bout of attention devoted to it. Although familiarity and expectedness are not synonyms, it is reasonable to argue that infants and adults have a higher expectation of seeing a familiar than a less familiar event (Cycowicz \& Friedman, 2007).

One problem with the assumption that unexpected events always recruit more prolonged attention than expected ones is that the infants' behaviors do not always conform to that prediction. For example, 4-month-old infants who saw a photo of their mother alongside a photo of an unfamiliar woman looked longer at the more familiar parent. They also looked longer at pictures of faces that had the familiar, ecologically valid arrangement of facial features than at faces with the features rearranged, even though the latter were less familiar and therefore less expected. By contrast, 1-year-olds devoted longer bouts of attention to a rearranged face than to a familiar face because their schemata for faces had become much 
firmer and, as a result, the rearranged faces were now optimally discrepant (Kagan, 2002). Seven-monthold infants looked longer at the vocal source of short sentences containing words they had been familiarized with a day earlier than at the source of spoken sentences containing totally unfamiliar words (Houston \& Jusczyk, 2003), and looked longer at a face whose perceptual form matched a vocalization than at a face paired with a discordant vocal sound (Soken \& Pick, 1999). These data suggest that the relation between expectation and duration of attention is often curvilinear, rather than linear, when the event is simple, not part of a complex sequence, and there is a minimal burden on the infant's working memory.

Even newborn infants honor this principle. Samples of newborns were familiarized with the nonsense word titi played from one of the two speakers placed on either side of the infant's head. The newborns turned their head to the initial presentation of the word. After habituation, the infants heard either the same word or one of the four variations created by altering the fundamental frequency of the original sound by $7 \%, 14 \%, 21 \%$, or $28 \%$. The infants were most likely to orient to a stimulus that altered the fundamental frequency by $14 \%$ or $21 \%$ (moderate discrepancies) and less likely to orient to the more extreme alteration (Weiss, Zelazo, \& Swain, 1988; see also Fenwick \& Morrongiello, 1998; Saffran, Loman, \& Robertson, 2000). Three-week-olds looked longer at $2 \times 2$ checkerboards than at $8 \times 8$ and $24 \times 24$ designs; 8 -week-olds looked longest at $8 \times 8$ checkerboards; and 14-week-olds stared longest at the $24 \times 24$ forms (Brennan, Ames, \& Moore, 1966).

The curvilinear relation between duration of attention and discrepancy is found in older infants. Sevenmonth-olds were first familiarized with either a sphere or a cylinder. When infants struck a bright yellow padded lever, they were allowed a 2.5 -s view of either a sphere or a cylinder. After the infants had habituated and stopped striking the lever, they saw one of the four stimuli. The infants who had been familiarized on the sphere saw a pear-shaped object, club, cylinder, or irregularly shaped styrofoam object. The infants who had been familiarized on the cylinder saw the club, pear-shaped object, sphere, or styrofoam object. The profiles of attention revealed a curvilinear relation between degree of discrepancy from the acquired schema and duration of attention. Infants who had been familiarized on the sphere showed their longest bout of attention to the club, which was moderately discrepant from the sphere; the infants who had habituated on the cylinder showed their longest bout of attention to the sphere.
Few infants showed their longest bout of attention to the styrofoam object, even though it was maximally discrepant and, therefore, minimally expected (Hopkins, Zelazo, Jacobson, \& Kagan, 1976; see Saffran \& Thiessen, 2003 for affirmation of this idea with multisyllable utterances).

McCall and McGee (1976), who examined many studies on the relation between discrepancy and attention, concluded, "There are at least seventeen separate samples of infants that displayed the inverted U-discrepancy function. Seventeen exemplars of one specific quadratic curve would appear to make the discrepancy hypothesis plausible and worthy of further examination" (p. 13).

\section{Maturation}

The term maturation refers to a uniform progression of changes in brain organization and function in infants growing in any reasonably natural environment. Some of these changes are detailed in a later section. The point to be made here is that the maturational changes that occur between 2 and 3 months affect the relation between looking time and familiarity because infants 4 months or older are more likely than younger infants to relate an event to an established schema. Two-, 4-, and 6-month-old infants sat across from an unfamiliar woman who either interacted with the infant as a parent would or sat with an immobile face displaying a neutral, happy, or sad expression. Because the less mature 2-month-olds did not relate either event to their acquired schemata they looked equally long at both events. The 4-month-olds, who did relate the events to their schemata, devoted longer attention to the stranger when she was behaving like a parent because this posture was moderately discrepant from their past experience; whereas, the immobile posture was too novel and an attempt at assimilation was inhibited (Rochat, Striano, \& Blatt, 2002). Two-month-olds are also too immature to perceive an object partially hidden by an occluder as a unitary entity (Johnson et al., 2003) and behave as if they do not expect an object in midair, with no visible support, to fall to a surface (Sitskoorn \& Smitsman, 1995). Children will revise that belief when they learn later about astronauts taking space walks.

The maturational changes that occur between 6 and 10 months are accompanied by the introduction of a new process governing attention. Kagan, Kearsley, and Zelazo (1978) demonstrated, over 25 years ago, that holding the stimuli constant, there was a U-shaped function between age and duration of attention across the interval from 4 to 12 months, with a nadir between 6 and 9 months, followed by 
increased attention to the same events for the rest of the 1st year. Courage et al. (2006) replicated this result with eight different categories of visual stimuli. Other evidence suggests that the enhanced ability to hold a schema for a past event in a working memory circuit and to relate a present event to that schema and to representations acquired in the past are critical additions to the infant's talents at this time (Diamond, 1990; Kagan \& Herschkowitz, 2005). As a result, infants older than 8 or 9 months are likely to create a perceptual prototype for frequently experienced events and to ignore discrepancies in single features that do not alter the holistic, gestalt quality of the schema. By contrast, infants less than 8 months often treat discrepancies in single features more seriously (Doupe \& Kuhl, 1999; see also Weikum et al., 2007).

\section{The Role of the Stimulus}

Many experiments are insufficiently attentive to the physical features of the stimuli presented to infants because they are not of primary interest to the scientist. Ross and Dannemiller (1999) note that motion, color contrast, and luminance compete for the young infant's attention because the brain always reacts to the physical features of an event independent of its meaning. For example, removing or muting the contrast between the color of the background and the color of the target stimulus can affect looking behavior in a significant way. Arrays containing stimuli with red features usually recruit more attention than those with green or blue features, but investigators often ignore this fact when they select the stimuli for their experiments (see e.g., Shimizu \& Johnson, 2004). Adults viewing curved or angular versions of neutral objects showed greater blood flow (implying activation) to the amygdala, superior temporal gyrus, anterior cingulate, and select visual areas to the angular compared with the curved forms (Bar \& Neta, 2007). Thus, infants might look longer at a toy block than at a hand after seeing a beanbag move spontaneously (without obvious provocation) because the block contained more linear, angular features than the hand and, therefore, might have activated brain sites that provoke a prolonged bout of attention. (See Saxe, Tzelnic, \& Carey, 2007, who did not acknowledge this possibility.)

\section{The Concept of Number}

I now consider in more detail the evidence behind three classes of claims that do not differentiate between schematic and semantic representations, fail to acknowledge the importance of the source of evidence, or are indifferent to the physical features of the stimulus arrays. The three claims refer to young infants' possession of the concept of number, physical impossibility, and permanent objects. The concept of number is considered first. Some scientists attribute to young infants a concept of number, as contrasted with a perceptual representation of quantity because they can distinguish between displays of different numbers of dark circles in a habituation - dishabituation design. However, Fantz and Fagan (1975) noted, over 30 years ago, that young infants look longer at a design with 20 squares than at one containing only 4 squares because of differences in the amount of contour derived from a combination of the size of each element and the number of elements.

Mix, Huttenlocher, and Levine (2002), who reviewed the literature on the concept of number, concluded that the infant's ability to discriminate among different numbers of elements, as long as the numbers were less than four or five, was based primarily on perceptual features, especially total area, size, and density of the elements, and total contour length (see Tan \& Bryant, 2000, for a similar conclusion). When these physical properties were controlled, 6-month-olds behaved as if they could not discriminate between one and two objects (Xu, Spelke, \& Goddard, 2005). These observations imply that the infant's ability to perceive differences in the size and density of elements and amount of contour is qualitatively different from the older child's symbolic concept of number (see Feigenson, Carey, \& Spelke, 2002). Indeed, in some contexts, 12-month-olds behave as if they can only create and hold in working memory perceptual representations for up to three objects (see Ross-Sheehy, Oakes, \& Luck, 2003). One-year-olds who see an examiner place four crackers in a box do not persevere in searching for additional crackers after retrieving the first one, but will do so if they see the examiner place only two crackers in the box, implying that they regard any quantity of cracker greater than three as belonging to a single, amorphous category (Feigenson \& Carey, 2005). Le Corre and Carey (2007) suggest that the representation of the cardinal numbers that children use when they count is not an obvious derivative of the infants' perceptual representations of quantity.

My front lawn has eight trees, a fact I was unaware of until moments ago when I counted them. But when I gaze out the window in summer, I do not see a set of eight objects, but an array of tall green-gray objects in the context of a sloping, green lawn. Major changes occur between the infant's perceptual ability to discriminate between arrays of three and six circles and 
a 10-year-old knowing that an array of three circles can, if one wished, be named with the semantic concept " 3 ," which is symbolic of a magnitude less than the concept " 4. " Infants and adults would probably perceive a pile of playing cards composed of two full decks similarly, but only the adults know that they can conceptualize this event as one pile, two decks, or 104 cards.

Number is not an inherent property of a visual experience but one that is imposed on an event. An infant who discriminated between a cup three-fourths full of liquid and one one-fourth full does not possess the mathematical concept of fractions. Attributing number concepts to infants simply because they can discriminate among arrays containing different numbers of elements is analogous to attributing a number competence to pigeons who can be taught to peck at a key exactly four times (Machado \& Rodrigues, 2007), to the sensory cells of the basilar membrane because they respond differently to varied sound frequencies, and to honeybees, whose behavior upon returning to the hive is affected by the distance between the hive and a flower bed.

If the claim that infants possess a concept of number, as contrasted with schemata for varied arrays of elements, is suspect the suggestion that young infants can "add" numbers must also be vulnerable to criticism. Wynn $(1992,1998)$ has written that young infants possess a mental mechanism devoted especially to number and can "add numerical quantities." The evidence for this bold declaration is that young infants looked longer at a stage containing one doll than at one with two dolls after seeing a sequence in which a human hand placed a second doll on a recently curtained stage that had contained one doll. But Wynn presented the infants with only two test events-either one or two dolls-and did not allow them a choice between one, two, or no dolls. Infants pay little attention to a stage containing no dolls, even though this is an unexpected events for infants who were administered the addition procedure (Cohen \& Marks, 2002). This observation should raise some doubt regarding the claim that infants can add numbers. (See Bogartz et al., 1997, for another example of the importance of presenting more than two test events.) It is also relevant that the profile of attention shown by 5-month-old boys administered a partial replication of Wynn's procedure did not support her conclusion (Moore \& Cocas, 2006).

More important, if infants were able to add numbers it should make no difference if they first saw an object on a stage and then saw a second object added behind a screen (Wynn's procedure) or initially saw no object on the stage but watched two objects being added sequentially to a stage located behind a screen. However, 8-month-olds exposed to this procedure did not behave as if they could add $1+1$ (Uller, Carey, Huntley-Fenner, \& Klatt, 1999). Furthermore, 3-yearolds behave as if they do not "know" an essential feature of the concept of number; namely, that the number of objects in an array remains the same despite a change in their spatial arrangement (Halford \& Boyle, 1985). If preschool children do not possess this essential property of number, one can question the conclusion that the infants' representations of dolls moving on and off a stage share important features with the concept of number held by schoolaged children. Notice that Wynn could have written that infants are able "to combine schemata for two visual events and hold the combined representation in a short term memory circuit." This conclusion would be less vulnerable to criticism, though still requiring proof, but it would not have made the headlines of our major newspapers. The predicate "add" has a specific meaning in mathematics and psychologists cannot treat that definition permissively. Differentiate and integrate have specific meanings in the calculus that are not the meanings understood by social psychologists.

It also remains a possibility that other processes operative in Wynn's procedure can explain the data. One such process involves the curvilinear discrepancy principle. The last event the infants saw in the procedure for addition was a single doll located at the edge of a curtained stage. The test event contained either two dolls or one doll in the middle of a stage with no curtain. One can argue that a single doll in the middle of a stage with no curtain is moderately discrepant from the last event the infant saw, whereas two dolls are more discrepant. Hence, looking at one doll would be predicted by the curvilinear principle.

Second, young infants often look at the more familiar event after seeing a sequence of new experiences. In the procedure for addition, three distinct events occurred before the test trial and on two of those occasions, the infants saw one doll and never saw two dolls. Thus, they might have looked longer at one rather than two dolls on the test trial because it was the more familiar event and not because they expected to see two dolls.

Furthermore, Cohen and Marks (2002) remind us that young infants usually look longer at the most recent, rather than at the more remote, event when exposed to a sequence of events the investigator assumes is perceived as connected because the young infants forgot the initial experience. Six to 7month-olds first watched two different objects placed 
sequentially behind separate occluders on distinct places on a stage. Although they showed increased attention when the object that had been hidden last changed shape and color, they failed to do so when the object placed first behind the occluder underwent the same change (Kaldy \& Leslie, 2005). The authors argued that infants less than 9 months, before the maturational transition associated with an enhancement of working memory, have difficulty retrieving the initial events of a sequence. The last event Wynn's infants saw in the addition procedure was a single doll. A similar interpretation can be applied to a later study with 9-month-olds watching films of five geometric forms moving or emerging from behind an occluder (McCrink \& Wynn, 2004).

The young infant's ability to retain schemata for events experienced many seconds earlier and to retrieve them in the service of processing a new event, grows linearly during the 1st year (Fox, Kagan, \& Weiskopf, 1979; Pelphrey et al., 2004; Ross-Sheehy et al., 2003). Most infants under 7 months have difficulty remembering the location of an object when there is only a 7- to 10-s delay between the hiding of the object and the time when the infant is allowed to reach for it because the connectivity of medial temporal lobe structures and prefrontal cortex is immature (Diamond, 1990). Infants younger than 8 months looking at pairs of faces consisting of one unchanging photo and a series of different unfamiliar faces required more than $60 \mathrm{~s}$ of exposure to the unchanging face before they looked consistently longer at the novel stimulus (Rose, Feldman, \& Jankowski, 2002; see also Rose, Feldman, \& Jankowski, 2001). Children less than 3 years old typically do not integrate relevant past experiences with their understanding of the present moment (Povinelli, Landry, Theall, Clark, \& Castille, 1999).

In light of this evidence, it is surprising that Dehaene (2007) writes that psychological phenomena cannot be understood fully until they "have been related to all levels of brain organization" (p. 29) and contends that infants possess a concept of number localized in the intraparietal region of the brain. I assume Dehaene means that there should be a close correspondence between the behavioral and the biological evidence. If Dehaene is correct, the hypothesis localizing number in the intraparietal region of the infant's brain is suspect. First, the biological changes that occur in this region and in its connections after the 1st year could alter its functions. Second, native adult Chinese and English speakers show different patterns of brain activity while solving addition problems (Tang et al., 2006). Third, adults required to select the most likely answer (from two alternatives) to a series of multiplication problems showed the largest increase in blood flow in precentral and inferior gyri and displayed a decrease in blood flow to the intraparietal area (Ischebeck, Zamarian, Egger, Schocke, \& Delazer, 2007). Fourth, a major function of the intraparietal area involves the perception of a spatial array of objects, mediated primarily by the right hemisphere (de Schonen \& Mathivet, 1990; Hagler, Riecke, \& Sereno, 2007). The fact that the intraparietal area is active when humans see a display of four circles is more properly described as a response to a spatially distributed array of discrete stimuli rather than a reaction to the recognition that there are four objects. Blood flow profiles to the intraparietal area were different to spatially distinct arrays of three objects (one array grouped two of the objects and the other did not; Xu \& Chun, 2007). If this cortical area "counted" the number of objects, the blood flow patterns should have been similar to both arrays because they contained the same number. Furthermore, the cortical areas activated when adults were looking at arrays with varied numbers of objects were different from the areas active when they were reading numbers (Roux, Lubrano, Lauwers-Cances, Giussani, \& Demonet, 2008). These facts, and others, are inconsistent with the hypothesis that the infant's behavior to visual displays varying in number of elements reflects a competence that is similar to the older child's concept of number when doing arithmetic calculations.

\section{Inferring Physical Impossibility}

The claim that infants "know" that solid objects cannot pass through a solid barrier has also generated strident debate and readers are referred to volume 1 of the journal Infancy for a set of important articles, both pro and con, on this issue (Aslin, 2000). Baillargeon (1994) believes that infants less than 8 months old know that one solid object cannot pass through another. In one experiment, 6.5-month-olds watched a screen move in a 180-degree arc on a stage, resembling the motion of a drawbridge. The examiner then placed a solid box behind the screen to inform the infant that the screen could no longer traverse the full 180 degrees because the box would obstruct its passage. On the test trial, some infants saw the screen traverse 157 degrees, an impossible event; others saw the screen move in an arc of 112 degrees, which is a possible event. The infants looked longer at the impossible event. But the last dynamic event the infant saw was the screen moving in an arc of 180 degrees; therefore, seeing it move 157 degrees was 
more similar to that event than the 111 degree motion and, in addition, involved more motion (Baillargeon, 1994). Infants who saw a screen move 112 or 180 degrees in a setting where both were possible events looked longer at the event with more motion, that is, the 180 degree movement (Rivera, Wakely, \& Langer, 1999). Baillargeon suggested, however, that her evidence does not mean that infants respond to physical events "in terms of abstract underlying principles, but in terms of concrete categories corresponding to specific ways in which objects behave or interact" (p. 139). I interpret "concrete categories" to mean perceptually based schemata rather than semantically based conceptual representations of physical impossibility.

Schilling (2000) recognized that 4-month-olds might require a great deal of experience to create a firm schema for the complicated scene of a moving screen and an obstructing object on a stage. Hence, he gave one group of infants 7 exposures to the screen moving the full 180 degrees and gave another group 12 exposures to the same sequence. Schilling then placed an obstructing object on the stage (but one less salient than the brightly colored block used by Baillargeon, 1994) and had the screen rotate either 180 degrees or 112 degrees. The infants who had only seven exposures and therefore may not have habituated to the sequence, looked longer when the screen moved a full 180 degrees, the impossible event. However, the infants who had seen the 180 degree movement 12 times, and therefore were more likely to be bored, looked longer when the screen moved 112 degrees, the possible event that was discrepant from their more firmly formed schemata for the full 180 degree traverse. (See Baillargeon, 2000, for a rebuttal to Schilling, 2000.)

Schoner and Thelen (2006) have also questioned Baillargeon's (1994) conclusion that differential looking is a sufficient basis for assuming that infants know one object cannot pass through another. These scientists prefer the concepts of activation and inhibition fields, which vary continuously in strength and compete with each other. Schoner and Thelen assume that infants are prompted to look at a stimulus when the strength of the activation field motivating attention is stronger than the inhibition field motivating looking away. However, they agree with this author and others that the physical features of the stimulus and the timing and order of stimulus presentations can influence, in a serious way, the profiles of fixation time. These investigators have formalized the activation and inhibitory processes in a neural model that explains the evidence without reference to objects or physical impossibility.
In a second procedure designed to evaluate the infants' appreciation of physical impossibility, 7.5month-olds were familiarized on one of two displays of a ramp, a track, and an agent object that could contact a target object. The infants in the potential contact group saw the agent and target separated by a half barrier; hence, the former theoretically could contact the latter. The infants in the "no-contact" group saw a full barrier between the ramp and the track; hence, the agent could not contact the target. The test display, which was similar for both groups, presented infants with the top half of the barrier but the bottom half covered with a curtain, making it appear as if there were a full barrier between ramp and track. The agent rolled down the ramp, passed behind the curtain, and seconds later the target moved on the track. Because the no-contact group looked longer at this event than the contact group, the authors concluded that these infants "knew" the agent could not strike the target and cause it to move (Kotovsky \& Baillargeon, 2000). However, the test event was moderately discrepant from the familiarization experience for the no-contact infants because a curtain replaced the bottom half of the full barrier. The test stimulus was a more serious discrepancy for the "contact" group who had seen only a half-barrier during familiarization and no curtain. Thus, the curvilinear principle could account for these data.

It is also relevant that 6-month-olds did not show prolonged attention to a physically impossible movement sequence involving an agent and target object, and 10-month-olds, who saw both a possible and an impossible sequence without any prior familiarization, did not look longer at the physically impossible event (Oakes \& Cohen, 1990). Moreover, 10-montholds first familiarized on an impossible sequence behaved as if discrepancy was the primary determinant of attention for they looked longer at a possible sequence than at an impossible one (see Oakes, 1994, for a similar result).

Saxe and Carey (2006), who reviewed the research on the infant's ability to infer a necessary causal relation when an agent object contacts and dislocates a target object, concluded that infants become attentive when there is a violation of a perceptually based expectation of a target's movements, but they are not very attentive when the target changes color or state, suggesting that the target's motion has perceptual salience. Saxe and Carey suggested that perception of a "causal" relation between two events is not present at birth and, like the perception of the unity of an object, requires postnatal experiences. By the second half of the 1st year, infants have had a great deal of experience seeing hands throw or move objects and 
these experiences create schemata for hands as the origins of motion in another object. Hence, they look longer when a human hand is the agent that changes the object or location it approaches on a stage than when the agent is an oval green object (Shimizu \& Johnson, 2004). Infants can learn perceptual expectations with surprising speed (Kochukhova \& Gredeback, 2007). However, the important point is that the young infant's schematic representation of a sequence of physically plausible events is not a general competence but one that is limited to the classes of events that infants have encountered in the past. That is why the patterns of looking in 4-month-olds watching an object move in horizontal or diagonal trajectories, which included passing behind an occluder in a continuous or discontinuous trajectory, failed to support the hypothesis that young infants possess an understanding of the possible or impossible motions of objects (Bremner et al., 2007).

The expectation that an object will move when struck by another does not mean that infants understand why a movement did or did not occur (Schlottmann, 1999). Haith and Benson (1998) point out that when a moving object does not contact a target object and, following a brief delay, the latter moves (an impossible sequence), infants might be reacting to the difference in timing between the familiarization experience, in which there was simultaneity between the contact of agent with target and the subsequent motion of the target and the test event in which simultaneity was missing. Most 4-year-olds are unable to report the reasons why an impossible event cannot occur (Shtulman \& Carey, 2007). Older children have learned that morning light always follows the dark of night and would be surprised if there were no light when they woke at 8 a.m., but they do not believe that the latter was the cause of the former.

Preschool children who have seen restaurant scenarios on television are likely to have a perceptual schema for a sequence in which an adult writes down on paper what sitting adults say and, minutes later, delivers some food to the latter. Hence, they would be surprised if the waiter brought the customer a toy car. But that fact does not mean that the child "knows" anything about the chain of events that transpired between the perception of the adult writing on a pad and the later delivery of the food. Many adults have a perceptual schema for hitting the button on their computer and seeing, seconds later, the word Welcome on the screen. But they do not possess a conceptual representation of the causal sequences that occurred between the two events. Rats can acquire an expectation of receiving food when they strike a lever and might show behavioral signs of surprise if the food did not appear, but few scientists would claim that the animals possessed a representation of the causal relation between their actions and the delivery of a few pellets. There is a great deal of evidence to suggest that the first signs of the ability to infer the invisible events that might mediate an outcome do not emerge until the middle of the 2nd year (Kagan, 1981). Causality, as Hume understood, is a symbolic invention and is not contained in a perceptual schema.

It is important to appreciate that 2-year-olds, who have some language and an improved working memory, do not infer the correct location of a ball that rolls down an incline to strike a tall, clearly visible occluder. In this study, the examiner placed the occluder behind one of the four doors over a series of trials and asked the child to guess which door should be opened in order to retrieve the ball. Twoyear-olds could not solve this problem; that is, they were unable to infer the correct door to open from their perception of the location of the occluder (Berthier, De Bois, Poirier, Novak, \& Clifton, 2000). However, 2-year-olds do show increased attention if a puppet, who had been successfully retrieving a ball from the correct door, failed to reach for the object at the door representing the correct location (Mash, Novak, Berthier, \& Keen, 2006). Hood, Cole-Davies, and Dias (2003) performed a similar experiment with a similar result. Two-and-a-half-year-olds stared for several seconds when a toy that had rolled down a ramp and struck an occluder suddenly appeared on the other side of the occluder-a physically impossible event-but failed to search correctly for the toy at the place where the occluder rested.

These results affirm the earlier suggestion that the predicate "know" has two different meanings in these varied experimental contexts. One refers to prolonged attention following the violation of a perceptual expectation; the second refers to a conceptually richer representation that includes an inference representing a necessary relation between the location of an occluder and the location of an object. Because the 2-year-olds did not reach correctly for the object when they could see where the occluder rested, investigators may be going beyond the evidence when they conclude that infants less than 1 year "know" that objects cannot pass through a solid barrier and imply that "know" has the same meaning for infants that it has for older children.

\section{Object Permanence}

Eight-month-olds administered the Piagetian A not B task often stare briefly at the correct location of a hidden object but reach incorrectly (Ahmed \& 
Ruffman, 1998; Hofstadter \& Reznick, 1996). Some psychologists have used the staring response as evidence that infants "know" the correct location of the object. But neuroscientists have learned that the dorsal circuit, which influences the frontal eye fields in the left hemisphere and mediates the location of an event (the "where" circuit), matures earlier than the ventral circuit that mediates the representation of an object-qua-object (the "what" circuit; Campana, Cowey, Casco, Oudsen, \& Walsh, 2007; Rao, Zhou, Zhou, Fan, \& Chen, 2003). Knowing the location where an event just occurred is not equivalent to knowing that a particular object, seen hidden seconds earlier, is resting in that location. I will orient in the direction of a fast-moving object detected in my peripheral vision without having any knowledge of the features or category of the object. Hence, looking at the correct location where a toy had been hidden may not represent a point on a continuum of object permanence but rather a totally different cognitive process (Ruffman, Slade, Carlos-Sandino, \& Fletcher, 2005). Some dog breeds will run hundreds of yards to retrieve a stick thrown by their owner even though they cannot see the object they are racing to retrieve. It is not obvious that the dog knows that the stick is a permanent object that cannot disappear.

In summary, the increased fixation time observed after violation of a perceptual expectancy is influenced by at least six different factors, depending on experimental conditions: (a) the event seen last in a sequence and the timing of the events in the sequence, (b) the more familiar event in a complex sequence, (c) the more unfamiliar of two test events, (d) an unexpected event, (e) the moderately discrepant event when more than two unfamiliar events are presented, and always (f) the salient physical features of the event. No investigation, to my knowledge, has adequately controlled for all six factors. Hence, it is reasonable to question the claim that 4-month-olds have a concept of number, can add, and "know" why an object cannot pass through a solid substance. The same skepticism applies to the claim that infants know that an illustration of a cube, resembling an Escher drawing, is physically impossible to construct. Careful examination of the details in the possible and impossible cubes reveals subtle differences in their physical features (Shuwari, Albert, \& Johnson, 2007).

\section{Including Other Measures}

Because all conclusions are constrained by their source of evidence, it is relevant that measures other than total fixation time, including operant responding and changes in heart rate, skin conductance, and vagal tone, occasionally invite different inferences about an infant's knowledge (Bornstein \& Suess, 2000; Shields \& Rovee-Collier, 1992). The various waveforms in the event-related potential (ERP) also lead to different conclusions regarding the state of an infant following violation of an expectation. For example, 6-month-olds who saw, in a random series, a familiar and unfamiliar face, and a familiar and unfamiliar object showed a larger negative waveform at about $400 \mathrm{~ms}$ (called Nc) to the familiar events, but a larger positive slow waveform at about $800 \mathrm{~ms}$ to the unfamiliar stimuli (de Haan \& Nelson, 1999).

Infants between 4.5 and 7.5 months were first familiarized on two geometric forms (A and B) and later saw form $A$ on $60 \%$ of the trials, form B on $20 \%$ of the trials, and a third novel form (C) on $20 \%$ of the trials. The Nc waveform was largest to the novel form C. But had attention been coded in the usual fashion many infants would have looked longest at form B, the moderately discrepant event (Reynolds \& Richards, 2005). Infants familiarized on trios of objects that varied in shape, color, and orientation over trials failed to show an increase in attention to the unexpected appearance of two objects but did display a clear change in an ERP waveform to two objects (Arriaga, 2001). Finally, there was no correlation in 7-month-olds between the difference in fixation time to faces displaying a fearful compared with a happy expression (larger values to the fear face) and the differences in the magnitudes of the Nc or P400 waveforms to these two facial expressions, despite larger values to the fear face (Leppanen, Moulson, Vogel-Farley, \& Nelson, 2007; see de Haan \& Nelson, 1997; Slater, Morison, \& Somers, 1988; Webb, Long, \& Nelson, 2005, for additional support of the claim that different conclusions follow from data on looking time compared with ERP evidence).

Vocalization, smiling, and changes in facial expression can also reflect psychological states provoked by violations of expectations that looking times fail to reveal. For example, infants looked longer at a speaker baffle playing the babbling of an unfamiliar infant than at one playing their own babbling, but the infants vocalized more to the latter event, even though they did not usually hear tape recordings of infant babbling and, therefore, both events were unexpected. Fourmonth-olds playing peek-a-boo with an adult who suddenly displayed a sad, rather than a smiling, face showed no change in fixation time but displayed a change in facial expression (Montague \& WalkerAndrews, 2001). On occasion, smiling reflects recognition of a discrepant event when fixation time does not. Three-month-olds showed equivalent fixation times to 
pictures of a normal face and a face with a single cyclopean eye in the middle of the forehead but only smiled to the regular face (Lewis, 1967).

Prolonged attention to an event appears to reflect the state created by an event that engages a schema but is not assimilated immediately. Babbling or smiling reflects the state created by a discrepant event that is easier to match to a schema and is assimilated more rapidly (Kagan et al., 1978). Moreover, the combination of fixation time and smiling, coded simultaneously, was the best predictor of how many exposures to a familiarization stimulus were required before 5- to 9-month-old infants looked reliably longer at the novel member of a pair of events (Rose, Futterweit, \& Jankowski, 1999).

An elegant experiment with monkeys revealed the inferential error that is possible when investigators use only one measure to evaluate a cognitive process or structure. Four rhesus monkeys were trained over many days to make a simple motor response whenever a particular human face appeared on a screen. After the animals had learned to discriminate this face from many others, the psychologists altered the features of this target face in order to discover the essential features of the monkeys' schema for the familiar face. As expected, the animals were less likely to make the motor response (indicating recognition) when the size or location of the eyes was altered than when there were alterations in the nose or chin, suggesting that the size and placement of the eyes were the most essential features of the monkeys' schema for the target face. But, surprisingly, some animals showed no change in behavior to a face with no eyes at all and behaved as if this stimulus were the target face (Keating \& Keating, 1993).

This unexpected result invites one reasonable and one unreasonable explanation. The latter implies that monkeys perceive faces in a manner that is qualitatively different from humans; no child would treat a face with no eyes as equivalent to one with eyes. If this explanation were correct, a great deal of theory would have to be rewritten. Hence, the more reasonable interpretation is that the monkey's behavior is ambiguous in meaning and can be evoked by more than one psychological state. I suspect this is the proper inference and, therefore, urge more caution among scientists who make claims about what infants know that are based on only one measure, whether that measure is fixation time, instrumental kicking, ERPs, autonomic response, smiling, or babbling. There is, at present, no behavioral or biological reaction that is restricted to a single set of conditions and demands only one inference. Readers are reminded of the earlier commitment by behaviorists to the concept of the strength of a habit. However, this a priori concept lost its attractiveness when research revealed that the three measures of habit strength in a hungry rat-speed of running down an ally to a goal box, making the correct turn in a maze, and amount of food consumed after arriving at the goal—were not highly correlated.

\section{Influence of Brain Maturation}

The lawful alterations in brain structure, chemistry, and physiology over the first decade raise the possibility of qualitative changes in the psychological structures that represent objects, number, or causality in infants compared with older children (Lenroot \& Giedd, 2007). If the brains of 6-month-olds were essentially similar to those of 16-year-olds, the nativist argument would be more attractive, but this is not the case (Almli, Rivkin, McKinstry, \& the Brain Development Cooperative Group, 2007). For example, during the second half of the 1st year, there is a major spurt of differentiation in both pyramidal and inhibitory interneurons in the prefrontal cortex, a broader distribution of the double bouquet interneurons in Layer 3, an increase in the number of spines and extra large excrescences on the proximal dendrites of pyramidal cells in the CA3 region of Ammon's horn of the hippocampus, and increased glucose uptake in the lateral, frontal, and dorsolateral prefrontal cortex (Chugani, 1994; Huttenlocher, 1974, 1990; Kostovic, 1987, 1990; Mrzljak, Uylings, Van Eden, \& Judas, 1990). Furthermore, the connections between the amygdala-temporal lobe and the prefrontal cortex are strengthened during the second half of the 1st year, in part because axons within the capsula interna develop myelin (Brody, Kinney, Kloman, \& Gillis, 1987; Chrousos \& Gold, 1992). It cannot be a coincidence that these structural changes occur at the same time psychologists observe a significant improvement in working memory (Reznick, Morrow, Goldman, \& Snyder, 2004). These biological changes permit 1-yearolds to hold representations of experience in an active state for a longer time and to retrieve representations of events that occurred 10-30 s earlier (Kagan \& Herschkowitz, 2005; Seress \& Mrzljak, 1992; Witter, 1993).

Not surprisingly, these structural changes are accompanied by changes in power in the electroencephalogram (EEG) and ERPs. For example, a working memory task (Piaget's A not B problem) administered to 8-month-olds evoked changes in power across the entire cortex, whereas a working memory task administered to 4-year-olds was associated with more localized changes in power restricted to medial frontal sites 
and increased coherence between frontal and temporal-occipital sites (Bell \& Wolfe, 2007). The various waveforms of the ERP also undergo a major change between 3 and 24 months (Jing \& Benasich, 2006; Richards, 2003; Scott, 2006; Webb et al., 2005), and the amplitudes of the P2/N2 waveform to click sounds increase in a linear fashion between 1 and 12 months (Ohlrich \& Barnet, 1972). In addition, the proportion of quiet sleep associated with sleep spindles $(12-14 \mathrm{~Hz})$ increases in precentral sites at 9-10 months (Tanguay, Ornitz, Kaplan, \& Bozzo, 1975).

The brain continues to mature after the first birthday. Blood flow is greater to the right than to the left hemisphere during the opening 3 years but shifts to more predominant flow to the left hemisphere at about 4 years of age (Chiron et al., 1997). Synaptic density in the primary auditory cortex does not reach adult values until puberty; dendrites on neurons of the dentate nucleus of the cerebellum undergo intensive lengthening and extension, and the basal ganglia continue to develop during the 2nd year. Dopamine receptors in the caudate nucleus (especially D1 and D2 receptors) do not reach maximal density until the middle of the 2nd year and the neurons of Cortical Layer 3, which comprise the cells of the corpus callosum, increase in size during this interval (Huttenlocher \& Dabholkar, 1997).

The concentration of the enzyme involved in the synthesis of acetylcholine increases sharply during the 2nd year when pyramidal neurons begin to express acetylcholinesterase in cell bodies and fibrillary networks (Black, 1991; Blokland, 1996). The innervation of Layer 3 pyramidal neurons by acetylcholinesterase and the growth of Layer 3 neurons probably contribute to the seminal advances of the 2nd year, especially the emergence of language, a moral sense, and self-awareness (Kagan, 1981; Mesulam \& Geula, 1991). Finally, the human brain does not attain $90 \%$ of its adult weight until 7 or 8 years of age (Giedd et al., 1999), the density of D1 receptors in the basal ganglia does not attain peak density until 4-8 years (Seeman et al., 1987), the degree of coherence of various EEG frequency bands between frontal and occipital or temporal areas increases after the third birthday, and the latency to the peak value of the N170 waveform to faces decreases by as much as $10 \%$ between 5 and 7 years of age (Taylor, McCarthy, Saliba, \& Degiovanni, 1999).

In sum, between the first and the eighth birthdays, the human brain attains peak synaptic density, maximal glucose uptake in the prefrontal cortex, peak concentrations of dopamine and norepinephrine receptors, myelination of long cortical tracts, coherence in the EEG, and maximal differentiation of dendrites in the hippocampus. It seems reasonable to suggest that these changes are accompanied by qualitative transformations of the cognitive functions of infants.

\section{Final Summary}

The most enthusiastic advocates of a return to nativism do not insist that the infants' concepts for number, physical impossibility, causality, or the permanence of objects are essentially the same as those of adolescents. The central suggestion in this article is that the perceptual representations that comprise schemata are to be distinguished from the conceptual structures involving semantic forms and inferences about events that were not experienced. Infants turn away from dissonant musical chords but do not possess the musician's concept of dissonance; infants who grasp an object placed in their palm do not understand the concept "mine." Spelke (1994), an influential advocate and sophisticated experimental psychologist, reminds us that there is no consensus as to when particular knowledge structures appear, how they are altered with growth and experience, what role the infants' representations play in the later development of thought and reason, and adds, wisely, that the infants' cognitive functioning has to differ from that of adults because "distinct knowledge systems are less interconnected" during the 1st year of life (Spelke, Vishton, \& Von Hofsten, 1995, p. 177).

Hence, it is appropriate to ask why the notion that young infants possess conceptual talents resembling those of older children became attractive to a select cohort of developmental psychologists in such a short time. One speculative explanation is that there is a competition for dominance between the language networks of biology and those of the social sciences. The dramatic advances in molecular biology and neuroscience, which are to be celebrated, have led most biologists, but a smaller number of social scientists, to assume that the vocabulary of the brain sciences will prove to be more fruitful than the psychological concepts that emerge from brain activity and depend on the products of experience. This article has suggested that a construct purporting to explain a psychological competence as a process inherent in the infant's brain organization need not have the same meaning as one that explains a process requiring extensive experience. However, some younger scientists have become attracted to the language networks of biology and neuroscience because these domains have become challenging areas of inquiry that provide generous research funds to those who study the relation between biological and psychological 
outcomes. Scientists who study the relations between experience and psychological phenomena find it more difficult to gain support of their work. Even the most committed scientists are susceptible to the schedule of rewards. I suspect that some social scientists feel that the importance of their research is enhanced if their ideas and data can be classified as belonging to biology rather than psychology. The idea that mathematical and physical principles are represented in the brains of 6-month-olds seems to be a biological, rather than a psychological, fact.

A second reason is that psychologists have tried for many decades to specify the experiences that a maturing brain, with its biologically prepared sensory and motor skills, exploits as children develop new competences. Because investigators have not been as successful as they hoped, their frustration is reduced a little by declaring that the kernel of the conceptual ability was already present in the first half of the 1st year. If this suggestion were true, the difficult task of discovering the differences between the earlier and the later forms, and understanding how those differences were created, would recede into the shadows. If 4-month-olds already appreciate that some physical events are impossible, the fact that 3-year-olds possess a kernel of this principle becomes less of a mystery. However, this position is surprising in light of what biologists have learned about embryological development. The 3-week-old embryo possesses neither a convoluted cerebral cortex nor the structural changes that the secretion of steroid hormones will induce at a later time.

The next cohort of developmental psychologists interested in these questions should gather additional sources of evidence besides fixation time; these include ERPs, skin conductance, muscle tension, blood flow, changes in heart rate, smiling, and vocalizing. Second, they should try to discover, with crosssectional or longitudinal designs, the experiences necessary for actualization of the competences in older children that might assume a simpler form in infants (Campos \& Bertenthal, 1989). This evidence could illuminate the nature of the changes that occur between infancy and later childhood and clarify the degree of continuity or discontinuity between them.

If 2-year-olds cannot add the cardinal numbers 2 and 4 and do not know which door to open to retrieve a ball resting behind a visible occluder, it is possible that the apparently similar "knowledge" infants are presumed to possess is qualitatively different from that of the school-aged child. I agree with Aslin's (2000) suggestion that the nativist position remains viable until additional evidence clearly refutes or fails to reject this view. Additional research is required before psychologists can be certain of the degree of similarity in mechanism between the cognitive functions of infants and older children. My skepticism rests on the observation that it is rare, in any scientific domain, for a single measure to reveal all that is necessary to understand a phenomenon. Hence, it is reasonable to question the assumption that an increase in fixation time of a few seconds to an event that violates an acquired perceptual expectation, without any other evidence, is a sufficient basis for inferring that infants under 6 months possess a conceptual representation of number, physical impossibility, causality, or the permanence of objects that shares important features with the competences awarded the same name in older children.

\section{References}

Ahmed, A., \& Ruffman, T. (1998). Why do infants make A not $B$ errors in a search task, yet show memory for the location of hidden objects in a nonsearch task? Developmental Psychology, 34, 441-453.

Almli, C. R., Rivkin, M. J., McKinstry, R. C., \& the Brain Development Cooperative Group. (2007). The NIH MRI Study of normal brain development: Newborns, infants, toddlers, and preschoolers. Neuroimage, 35, $308-325$.

Arriaga, R. (2001). Behavioral and electrophysiological correlates of numerosity discrimination in eight-month-old infants. Unpublished doctoral dissertation, Harvard University, Cambridge, MA.

Aslin, R. N. (2000). Why take the cog out of infant cognition? Infancy, 1, 463-470.

Aslin, R. N. (2007). What's in a look? Developmental Science, $10,48-53$.

Baillargeon, R. (1994). How do infants learn about the physical world? Current Directions in Psychological Science, 3, 133-140.

Baillargeon, R. (2000). Reply to Bogartz, Shinskey, and Schilling; Schilling; and Cashon and Cohen. Infancy, 1, 447-462.

Bar, M., \& Neta, M. (2007). Visual elements of subjective preference modulate amygdala activation. Neuropsychologia, 45, 2191-2200.

Beeman, M., \& Chiarello, C. (1998). Right hemisphere language comprehension. Mahwah, NJ: Erlbaum.

Bell, M. A., \& Wolfe, C. D. (2007). Changes in brain functioning from infancy to early childhood. Developmental Neuropsychology, 31, 21-38.

Berthier, N. E., De Bois, S., Poirier, C. R., Novak, M. A., \& Clifton, R. K. (2000). Where's the ball? Developmental Psychology, 36, 394-401.

Black, I. B. (1991). Information and the brain. Cambridge, MA: MIT Press.

Blokland, A. (1996). Acetylcholine: A neurotransmitter for learning and memory. Brain Research Review, 21, $285-300$. 
Bogartz, R. S., Shinskey, J., \& Speaker, C. J. (1997). Interpreting infant looking: The event set $\mathrm{x}$ event set design. Developmental Psychology, 33, 408-422.

Bogartz, R. S., Shinskey, J. L., \& Schilling, T. H. (2000). Object permanence in five-and-one-half-month-old infants? Infancy, 1, 403-428.

Bornstein, M., \& Suess, P. E. (2000). Physiological selfregulation and information processing in infancy: Cardiac vagal tone and habituation. Child Development, 71, 273-287.

Bremner, J. G., Johnson, S. P., Slater, A., Mason, U., Cheshire, A., \& Spring, J. (2007). Conditions for young infants' failure to perceive trajectory continuity. Developmental Science, 10, 613-624.

Brennan, W., Ames, E. W., \& Moore, R. W. (1966). Age differences in infants' attention to patterns of different complexities. Science, 151, 354-356.

Brody, B. A., Kinney, H., Kloman, A., \& Gillis, F. H. (1987). Sequence of central nervous system myelination in human infancy. 1. An autopsy study of myelination. Journal of Neuropathology and Experimental Neurology, 46, 283-301.

Campana, G., Cowey, A., Casco, C., Oudsen, I., \& Walsh, V. (2007). Left frontal eye field remembers "where" but not "what." Neuropsychologia, 45, 2340-2345.

Campos, J. J., \& Bertenthal, B. I. (1989). Locomotion and psychological development in infancy. In F. Morrison, C. Lord, \& D. Keating (Eds.), Applied developmental psychology (Vol. 2, pp. 230-258). New York: Academic Press.

Cashon, C. H., \& Cohen, L. B. (2000). Eight-month-old infants' perception of possible and impossible events. Infancy, 1, 429-446.

Chiron, C., Jambaque, I., Nabbout, R., Lounes, R., Syrota, A., \& Dulac, O. (1997). The right brain hemisphere is dominant in human infants. Brain, 120, 1057-1065.

Chrousos, G. P., \& Gold, P. W. (1992). The concepts of stress and stress system disorders. Journal of the American Medical Association, 267, 1244-1252.

Chugani, H. T. (1994). Development of regional brain glucose metabolism. In G. Dawson \& K. Fischer (Eds.), Human behavior and the developing brain (pp. 153-175). New York: Guilford.

Cohen, L. B., \& Cashon, C. H. (2006). Infant cognition. In W. Damon \& R. M. Lerner (Series Eds.) \& D. Kuhn \& R. Siegler (Vol. Eds.), Handbook of child psychology (Vol. 2, 6th ed., pp. 214-251). New York: Wiley.

Cohen, L. B., \& Marks, K. S. (2002). How infants process addition and subtraction events. Developmental Science, 5, 186-201.

Courage, M. L., Reynolds, G. D., \& Richards, J. E. (2006). Infants' attention to patterned stimuli: Developmental change from 3 to 12 months of age. Child Development, $77,680-695$.

Cycowicz, Y. M., \& Friedman, D. (2007). Visual novel stimuli in an ERP novelty oddball paradigm. Psychophysiology, 44, 11-29.

de Haan, M., \& Nelson, C. A. (1997). Recognition of the mother's face by six-month old infants. Child Development, 68, 187-210. de Haan, M., \& Nelson, C. A. (1999). Brain activity differentiates face and object processing in six-month-old infants. Developmental Psychology, 35, 1113-1121.

Dehaene, S. (1997). The number sense. New York: Oxford University Press.

Dehaene, S. (2007). A few steps toward a science of mental life. Mind, Brain, and Education, 1, 28-47.

Deloche, G., Seron, X., Scius, G., \& Segui, J. (1987). Right hemisphere language processing. Brain and Language, 30, 197-205.

de Schonen, S., \& Mathivet, E. (1990). Hemisphere asymmetry in a face discrimination task in infants. Child Development, 61, 1192-1205.

Diamond, A. (1990). Developmental and neural bases of memory functions as indexed by the $A B$ and delayed response tasks in human infants and infant monkeys. Annals of the New York Academy of Sciences, 608, 267-309.

Doupe, A. J., \& Kuhl, P. K. (1999). Birdsong and human speech. Annual Review of Neuroscience, 22, 567-631.

Ellis, H. (1900). The analysis of the sexual impulse. Alienist and the Neurologist, 21, 247-262.

Fantz, R. L., \& Fagan, J. F. (1975). Visual attention to size and number of pattern details by term and pre-term infants during the first six months. Child Development, 46, $3-18$.

Feigenson, L., \& Carey, S. (2005). On the limits of infants' quantification of small object arrays. Cognition, 97, $295-313$.

Feigenson, L., Carey, S., \& Spelke, E. (2002). Infants' discrimination of number vs. continuous extent. Cognitive Psychology, 44, 33-66.

Fenwick, K. D., \& Morrongiello, D. A. (1998). Spatial colocation and infants' learning of auditory-visual associations. Infant Behavior and Development, 21, 745-760.

Fiske, J. (1883). The meaning of infancy. Boston: HoughtonMifflin.

Fox, N., Kagan, J., \& Weiskopf, S. (1979). The growth of memory during infancy. Genetic Psychology Monographs, 99, $91-130$.

Frick, M., \& Colombo, J. (1996). Individual differences in infant visual attention: Recognition of degraded visual forms by four-month olds. Child Development, $67,188-204$.

Giedd, J. N., Blumenthal, J., Jeffries, N. O., Rajapakse, J. C., Vaituzis, A. C., \& Liu, H. (1999). Development of the human corpus callosum during childhood and adolescence: A longitudinal MRI study. Progress in Neuropsychopharmacology and Biological Psychiatry, 23, 571- 588.

Hagler, D. J., Riecke, L., \& Sereno, M. I. (2007). Parietal and superior frontal visuospatial maps activated by pointing and saccades. Neuroimage, 35, 1562-1577.

Haith, M. M. (1998). Who put the cog in infant cognition? Infant Behavior and Development, 21, 167-179.

Haith, M. M., \& Benson, J. B. (1998). Infant cognition. In W. Damon (Series Ed.) \&D. Kuhn \& R. S. Siegler (Vol. Eds.), Handbook of child psychology (Vol. 2, 5th ed., pp. 199-254). New York: Wiley. 
Halford, G. S., \& Boyle, F. M. (1985). Do young children understand conservation of number? Child Development, $56,165-176$.

Hamburger, V. (1975). Changing concepts in developmental neurobiology. Perspectives in Biology and Medicine, 20, 162-178.

Hofstadter, M., \& Reznick, J. S. (1996). Response modality affects human infant delayed- response performance. Child Development, 67, 646-658.

Hood, B., Cole-Davies, V., \& Dias, M. (2003). Looking and search measures of object knowledge in preschool children. Developmental Psychology, 38, 61-70.

Hopkins, J. R., Zelazo, P. R., Jacobson, S. W., \& Kagan, J. (1976). Infant reactivity to stimulus schema discrepancy. Genetic Psychology Monographs, 93, 17-62.

Houston, D. M., \& Jusczyk, P. W. (2003). Infants' long term memory for the sound patterns of words and voices. Journal of Experimental Psychology, 19, 11431154.

Huttenlocher, P. R. (1974). Dendritic development in neocortex of children with mental defect and infantile spasms. Neurology, 24, 203-210.

Huttenlocher, P. R. (1990). Morphometric study of human cerebral cortex development. Neuropsychologia, 28, 517-527.

Huttenlocher, P. R., \& Dabholkar, A. S. (1997). Regional differences in synaptogenesis in human cerebral cortex. Comparative Neurology, 387, 167-178.

Ischebeck, A., Zamarian, L., Egger, K., Schocke, M., \& Delazer, M. (2007). Imaging early practice effects in arithmetic. Neuroimage, 36, 993-1003.

Ivry, R. B., \& Lebby, P. C. (1998). The neurology of consonant perception. In M. Beeman \& C. Chiarello (Eds.), Right hemisphere language comprehension (pp. 3-25). Mahwah, NJ: Erlbaum.

Jacobson, S. W. (1979). Matching behavior in the young infant. Child Development, 50, 425-430.

Jing, H., \& Benasich, A. A. (2006). Brain responses to tonal changes in the first two years of life. Brain Development, 28, 247-256.

Johnson, S. P., Bremner, J. G., Slater, A., Mason, U., Foster, K., \& Cheshire, A. (2003). Infants' perception of object trajectories. Child Development, 74, 94-108.

Jones, S. S. (1996). Imitation or exploration? Child Development, 62, $1952-1969$.

Joseph, J. E., Powell, D. K., Andersen, A. H., Bhatt, R. S., Dunlap, M. K., Foldes, S. T., et al. (2006). fMRI in alert behaving monkeys: An adaptation of the human infant familiarization novelty preference procedure. Journal of Neuroscience Methods, 157, 10-24.

Kagan, J. (1981). The second year. Cambridge, MA: Harvard University Press.

Kagan, J. (2002). Surprise, uncertainty, and mental structures. Cambridge, MA: Harvard University Press.

Kagan, J., \& Herschkowitz, N. (2005). A young mind in a growing brain. Mahwah, NJ: Erlbaum.

Kagan, J., Kearsley, R. B., \& Zelazo, P. R. (1978). Infancy. Cambridge, MA: Harvard University Press.
Kagan, J., Klein, R. V., Haith, M. M., \& Morrison, F. J. (1973). Memory and meaning in two cultures. Child Development, 44, 21-23.

Kagan, J., Linn, S., Mount, R., \& Reznick, J. S. (1979). Asymmetry of inference and the dishabituation paradigm. Canadian Journal of Psychology, 33, 288-304.

Kaldy, Z., \& Leslie, A. (2005). A memory span of one? Object identification in 6.5 month old infants. Cognition, 97, $153-177$.

Keating, C., \& Keating, E. G. (1993). Monkeys and mug shots. Journal of Comparative Psychology, 107, 131-139.

Kochukhova, O., \& Gredeback, G. (2007). Learning about occlusion: Initial assumptions and rapid adjustments. Cognition, 105, 26-46.

Kostovic, I. (1987). Late postnatal development of acetylcholinesterase-reactive innervation of layer III pyramidal neurons in human prefrontal cortex. Neuroscience, 22, S228.

Kostovic, I. (1990). Structural and histochemical reorganization of the human prefrontal cortex during perinatal and postnatal life. Progress in Brain Research, 85, $223-240$.

Kotovsky, L., \& Baillargeon, R. (2000). Reasoning about collisions involving inert objects in 7.5 month old infants. Developmental Science, 3, 344-359.

Le Corre, M., \& Carey, S. (2007). One, two, three, four, nothing more: An investigation of the conceptual sources of the verbal counting principles. Cognition, 105, 395-438.

Lenroot, R. K., \& Giedd, J. N. (2007). The structural development of the human brain as measured longitudinally with magnetic resonance imaging. In D. Coch, K. W. Fischer, \& G. Dawson (Eds.), Human behavior, learning, and the developing brain (pp. 50-73). New York: Guilford.

Leppanen, J. M., Moulson, M. C., Vogel-Farley, V. K., \& Nelson, C. A. (2007). An ERP study of emotional face processing in the adult and infant brain. Child Development, 78, 232-245.

Lewis, M. (1967). The meaning of a response or why researchers in infant behavior should be oriental metaphysicians. Merrill-Palmer Quarterly, 13, 7-18.

Lorenz, K. Z. (1958). The evolution of behavior. Scientific American, 199, 67-78.

Machado, A., \& Rodrigues, P. (2007). The differentiation of response numerosities in the pigeon. Journal of Experimental Analysis of Behavior, 88, 153-178.

Mandler, J. M. (2004). The foundations of mind: Origins of conceptual thought. New York: Oxford University Press.

Marcus, G. F., Vijayan, S., Rao, S., \& Vishton, P. M. (1999). Rule learning by seven-month-old infants. Science, 283, $77-80$.

Mash, C., Novak, E., Berthier, N. E., \& Keen, R. (2006). What do two-year-olds understand about hiddenobjects? Developmental Psychology, 42, 263-271.

McCall, R. B., Eichorn, D. H., \& Hogarty, P. S. (1977). Transitions in early mental development. Monographs of the Society for Research in Child Development, 42(Serial No. 171). 
McCall, R. B., \& McGee, P. (1976). The discrepancy hypothesis of attention and affect in infants. Unpublished manuscript.

McCrink, K., \& Wynn, K. (2004). Large-number addition and subtraction by 9-month old infants. Psychological Science, $15,776-781$.

Meltzoff, A. N., \& Moore, M. K. (1977). Imitation of facial and manual gestures by the human neomate. Science, 198, 75-78.

Mesulam, M. M., \& Geula, C. (1991). Acetylcholinesterase rich neurons in the human cerebral cortex: Cytoarchitectonic and ontogenetic patterns. Journal of Comparative Neurology, 306, 193-220.

Mix, K. S., Huttenlocher, J., \& Levine, S. C. (2002). Multiple cues for quantification in infancy. Psychological Bulletin, 128, 278-294.

Montague, D. P. F., \& Walker-Andrews, A. S. (2001). Peekaboo: A new look at infants' perception of emotion expressions. Developmental Psychology, 37, 826-836.

Moore, D. S., \& Cocas, L. A. (2006). Perception precedes computation. Developmental Psychology, 42, 666-678.

Moore, M. K., \& Meltzoff, A. N. (2004). Object permanence after a 24-hr delay and leaving the locale of disappearance: The role of memory, space, and identity. Developmental Psychology, 40, 606-620.

Mrzljak, L., Uylings, H. B., Van Eden, C. G., \& Judas, M. (1990). Neuronal development in human prefrontal cortex in prenatal and postnatal stages. Progress in Brain Research, 85, 185-222.

Nakagawa, A., Sukigara, M., \& Benga, A. (2003). The temporal relationship between reduction of early imitative responses in the development of attention mechanisms. BMC Neuroscience, 4, 33-50.

Oakes, L. (1994). Development of infants' use of continuity cues and their perception of causality. Developmental Psychology, 30, 869-879.

Oakes, L., \& Cohen, L. (1990). Infant perception of a causal event. Cognitive Development, 5, 183-207.

Ohlrich, E. S., \& Barnet, A. B. (1972). Auditory-evoked responses during the first year of life. Electroencephalography and Clinical Neurophysiology, 32, 161-169.

Pelphrey, K. A., Reznick, J. S., Goldman, B. D., Sasson, N., Morrow, J., Donahue, A., et al. (2004). Development of visuospatial short-term memory in the second half of the first year. Developmental Psychology, 40, 836-851.

Plunkett, K., Hu, J. F., \& Cohen, L. B. (2008). Labels can override perceptual categories in early infancy. Cognition, 106, 665-681.

Povinelli, D. J., Landry, A. M., Theall, L. A., Clark, B. R., \& Castille, C. M. (1999). Development of children's understanding that the recent past is causally bound to the present. Developmental Psychology, 35, 1426-1439.

Rakic, P. (1995). Radial versus tangential migration of neural clones in the developing cerebral cortex. Proceedings of the National Academy of Sciences, 92, 11323-11327.

Rao, H., Zhou, T., Zhou, Y., Fan, S., \& Chen, L. (2003). Spatiotemporal activation of the two visual pathways in form discrimination and spatial location. Human Brain Mapping, 18, 79-89.
Reynolds, G. D., \& Richards, J. E. (2005). Familiarization, attention, and recognition memory in infancy. Developmental Psychology, 41, 598-615.

Reznick, J. S., Morrow, J. D., Goldman, B. D., \& Snyder, J. (2004). The onset of working memory in infants. Infancy, $6,145-154$.

Richards, J. E. (2003). Attention affects the recognition of briefly presented visual stimuli in infants. Developmental Science, 6, 312-328.

Rivera, S. M., Wakely, A., \& Langer, J. (1999). The drawbridge phenomenon: Representational reasoning or perceptual preference? Developmental Psychology, 35, $427-435$.

Rochat, P., Striano, T., \& Blatt, L. (2002). Differential effect of happy, neutral, and sad, still faces on two, four, and six-month-old infants. Child Development, 11, $289-303$.

Rose, S. A., Feldman, J. F., \& Jankowski, J. J. (2001). Visual short-term memory in the first year of life: Capacity and recency effects. Developmental Psychology, 37, 539549.

Rose, S. A., Feldman, J. F., \& Jankowski, J. J. (2002). Processing speed in the 1st year of life: A longitudinal study of pre-term and full-term infants. Developmental Psychology, 38, 895-902.

Rose, S. A., Feldman, J. F., \& Jankowski, J. J. (2003). Infant visual recognition memory: Independent contributions of speed and attention. Developmental Psychology, 39, $563-571$.

Rose, S. A., Futterweit, C. R., \& Jankowski, J. J. (1999). The relation of affect to attention and learning in infancy. Child Development, 70, 549-559.

Ross, S. M., \& Dannemiller, J. L. (1999). Color contrast, luminance contrast, and competition in exogenous orienting in 3.5-month-old infants. Infant Behavior and Development, 22, 383-404.

Ross-Sheehy, S., Oakes, L. M., \& Luck, S. J. (2003). The development of visual short-term memory capacity in infants. Child Development, 74, 1807-1822.

Roux, F. E., Lubrano, V., Lauwers-Cances, V., Giussani, C., \& Demonet, J. F. (2008). Cortical areas involved in Arabic number reading. Neurology, 70, 210-217.

Ruffman, T., Slade, L., Carlos-Sandino, J., \& Fletcher, A. (2005). Are A-not-B errors caused by a belief about object location? Child Development, 76, 122-136.

Saffran, J. R. (2001). Words in a sea of sounds. Cognition, 81, 149-169.

Saffran, J. R., Loman, M. M., \& Robertson, R. R. W. (2000). Infant memory for musical experiences. Cognition, 77, 1315-1327.

Saffran, J. R., \& Thiessen, E. D. (2003). Pattern induction by infant language learners. Developmental Psychology, 39, 484-494.

Saxe, R., \& Carey, S. (2006). The perception of causality in infancy. Acta Psychologica, 123, 144-165.

Saxe, R., Tzelnic, T., \& Carey, S. (2007). Knowing who dunnit: Infants identify the causal agent in an unseen causal interaction. Developmental Psychology, 43, 149-158. 
Schilling, T. H. (2000). Infants' looking at possible and impossible screen rotations: The role of familiarization. Infancy, 1, 389-402.

Schlottmann, A. (1999). Seeing it happen and knowing how it works: How children understand the relation between perceptual causality and underlying mechanism. Developmental Psychology, 35, 303-317.

Schoner, G., \& Thelen, E. (2006). Using dynamic field theory to rethink infant habituation. Psychological Review, 113, 273-299.

Scott, L. S. (2006). Featural and configural face processing in adults and infants. Perception, 35, 1107-1128.

Seeman, P., Bzowej, N. H., Guan, H. C., Bergeron, C., Becker, L. E., \& Reynolds, G. P. (1987). Human brain dopamine receptors in children and aging adults. Synapse, 1, 399-404.

Sera, R., \& Smith, L. B. (1990). New evidence on the development of the word "big." Child Development, 61, $1034-1052$.

Seress, L., \& Mrzljak, L. (1992). Postnatal development of mossy cells in the human dentate gyrus. Hippocampus, 2, $127-142$.

Shields, P. J., \& Rovee-Collier, C. (1992). Long-term memory for context-specific category information at six months. Child Development, 63, 245-259.

Shimizu, Y., \& Johnson, S. C. (2004). Infants' attribution of a goal to a morphologically unfamiliar agent. Developmental Science, 7, 425-430.

Shtulman, A., \& Carey, S. (2007). Improbable of impossible? How children reason about the possibility of extraordinary events. Child Development, 78, 1015-1032.

Shuwari, S. M., Albert, M. K., \& Johnson, S. P. (2007). Discrimination of possible and impossible objects in infancy. Psychological Science, 18, 303-307.

Sitskoorn, M. M., \& Smitsman, A. W. (1995). Infants' perception of dynamic-relations between objects: Passing through or support? Developmental Psychology, 31, 437-447.

Slater, A., Morison, V., \& Somers, M. (1988). Orientation discrimination and cortical function in the human newborn. Perception, 17, 597-602.

Soken, N. H., \& Pick, A. D. (1999). Infants' perception of dynamic affective expressions. Child Development, 70, $1275-1282$.

Spelke, E. S. (1994). Initial knowledge. Cognition, 50, 431-445.

Spelke, E. S., \& Kinzler, K. D. (2007). Core knowledge. Developmental Science, 10, 89-96.

Spelke, E. S., Vishton, P., \& Von Hofsten, C. (1995). Object perception, object-directed action, and physical knowledge in infancy. In M. S. Gazzaniga (Ed.), The cognitive neurosciences (pp. 165-180). Cambridge, MA: MIT Press.

Tan, L. S. C., \& Bryant, P. (2000). The cues that infants use to distinguish discontinuous quantities: Evidence using a shift-rate recovery paradigm. Child Development, 71, $1162-1178$.

Tang, Y., Zhan, W., Chen, K., Feng, S., Ji, Y., Shen, J., et al. (2006). Arithmetic processing in the brain shaped by cultures. Proceedings of the National Academy of Sciences, 103, 10775-10780.

Tanguay, P. E., Ornitz, E. M., Kaplan, A., \& Bozzo, E. S. (1975). Evolution of sleep spindles in childhood. Electroencephalography and Clinical Neurophysiology, 38, 175-181.

Taylor, M. J., McCarthy, G., Saliba, E., \& Degiovanni, E. (1999). ERP evidence of developmental changes in processing of faces. Clinical Neurophysiology, 110, 910-915.

Tinbergen, N. (1951). The study of instinct. London: Oxford University Press.

Uller, C., Carey, S., Huntley-Fenner, \& Klatt, L. (1999). What representations might underlie infant numerical knowledge? Cognitive Development, 14, 1-36.

Valenstein, E. S. (2005). The war of the soups and the sparks. New York: Columbia University Press.

Walden, T., Kim, G., McCoy, C., \& Karrass, J. (2007). Do you believe in magic? Infants' social looking during violations of expectations. Developmental Science, 10, $654-663$.

Warrington, E. K., \& McCarthy, R. A. (1987). Categories of knowledge. Brain, 110, 1273-1296.

Webb, S. J., Long, J. D., \& Nelson, C. A. (2005). A longitudinal investigation of visual event-related potentials in the first year of life. Developmental Science, 8, $605-616$.

Weikum, W. M., Vouloumanos, A., Navarra, J., SotoFaraco, S., Sebastian-Galles, N., \& Werker, J. F. (2007). Visual language discrimination in infancy. Science, 316, 1159.

Weiss, M. J., Zelazo, P. R., \& Swain, I. U. (1988). Newborn response to auditory stimulus discrepancy. Child Development, 59, 530-541.

West, M. (1914). Infant care. Bureau of publication 8. Washington, DC: US Government Office.

Witter, M. P. (1993). Organization of the entorhinalhippocampal system: A review of current anatomical data. Hippocampus, 3, 33-44.

Wynn, K. (1992). Addition and subtraction by human infants. Nature, 358, 749-750.

Wynn, K. (1998). Psychological foundations of number: Numerical competence in human infants. Trends in Cognitive Science, 2, 296-303.

Xu, F., Spelke, E. S., \& Goddard, S. (2005). Number sense in human infants. Developmental Science, 8, 88-101.

Xu, Y., \& Chun, M. M. (2007). Visual grouping in human parietal cortex. Proceedings of the National Academy of Sciences, 104, 18766-18771. 
This document is a scanned copy of a printed document. No warranty is given about the accuracy of the copy. Users should refer to the original published version of the material. 